\title{
CELIA LEYTON, SU PINTURA INDIGENISTA, RETRATO DEL PATRIMONIO CULTURAL DEL PUEBLO MAPUCHE
}

\author{
Lorena Villegas*, Renzo Vaccaro** y Alex Mellado*** \\ Universidad Católica de Temuco
}

\begin{abstract}
RESUMEN
Esta investigación ofrece una mirada académica sobre aspectos destacables de la vida y obra de la artista Celia Leyton Vidal (Santiago de Chile, 1895-1975), quien desarrolló gran parte de su trabajo pictórico en la región de La Araucanía, situada en el sur de Chile. Tuvo un alto perfil en su labor como docente, artista investigadora y promotora de los valores culturales del pueblo mapuche. Realizó un profundo trabajo de campo que se evidencia en anotaciones, bosquejos, descripciones e interpretaciones de sus experiencias investigativas, las que le permitieron, además de crear un gran cuerpo de obra, producir textos (catálogos y una autobiografía) con el objeto de acercar a las personas los valores y virtudes de la cosmovisión mapuche, cultura y etnia que consideraba en grave riesgo de desaparecer. Una primera revisión biográfica ha develado el contexto de su formación académica, su condición de género y los referentes que orientaron sus perspectivas de representación visual y sus valores ético-sociales. Por último, este trabajo investigativo conforma un análisis formal y simbólico de una de sus creaciones pictóricas, específicamente un autorretrato, en donde se relevan algunas claves que permiten configurar el valor de su proyecto artístico y cultural. Palabras Clave: Celia Leyton, pintura indigenista, retrato, patrimonio cultural.
\end{abstract}

\section{CELIA LEYTON, HER INDIGENOUS PAINTING, PORTRAIT OF THE MAPUCHE'S CULTURAL HERITAGE}

\section{Abstract}

This research explores key aspects of the life and work of the Chilean artist Celia Leyton Vidal (Santiago de Chile, 1895-1975). Celia Leyton's research and painting work was mainly developed in La Araucanía, the southern Chilean region where she spent most of her adult life. As a prominent middle school teacher, art researcher and painter, Leyton made a significant contribution to the academic art domain, and was devoted to the promotion and dissemination of the Mapuche culture and values. Her prolific field work includes annotations, sketches, descriptions and analysis of her research experiences, all of which led to the creation of numerous paintings and documents, including catalogues and an autobiography. Fearing it was endangered in modern times, the artist devotedly dedicated her entire life and work to disseminate Mapuche culture, virtues and worldview. A first biographic review provided a general understanding about the painter's life, her academic background, gender-related struggles, as well as the influential references that contributed to shape her social and ethical profile, and her visual representations and symbolism. Finally, we discuss a formal and symbolic analysis of a self-portrait, considered as one of her most important art works, and which reveals the true value of her artistic and cultural project.

KEYwORDs: Celia Leyton, indigenous painting, portrait, cultural heritage. 


\section{INTRODUCCIÓN ${ }^{1}$}

Este artículo presenta una mirada general sobre aspectos considerados relevantes para poner en valor la vida y obra de la artista chilena Celia Leyton Vidal. Esta mirada general de su obra establece algunas bases que posibilitan una comprensión más amplia de sus ideas y motivaciones en el campo artístico desarrolladas en la primera mitad del siglo xx en Chile.

Celia Leyton Vidal (Santiago de Chile, 1895-1975) fue una artista visual que desarrolló gran parte de su trabajo en la región de La Araucanía, en el sur de Chile. Tuvo un rol activo en la plástica nacional; sin embargo, su vida y obra han sido poco investigadas, generándose un silencio historiográfico de su legado. Uno de los factores que pudieron haber influido en su bajo reconocimiento es la lejanía geográfica en la cual ella desarrollaba su trabajo, situado en la ciudad de Temuco. En este contexto era muy complejo lograr notoriedad artística estando lejos de la escena plástica que se desarrollaba en Santiago. Otros de los factores que pudieron haber contribuido en su bajo reconocimiento son los temas en los cuales ella centró su obra, focalizados en representar costumbres y personajes de la cultura mapuche, motivo pictórico que estaba distante de las temáticas que se desarrollaban en la plástica nacional de esa época. Momento también de absoluto dominio de «lo masculino" en el circuito de las artes nacionales e internacionales, tanto en la producción de obra como de crítica y de formación académica.

Este artículo está centrado en tres ejes. El primero corresponde a una revisión biográfica de Celia Leyton que permite establecer su contexto de formación académica, su condición de género y los referentes que determinaron sus perspectivas de representación visual. El segundo eje aborda los alcances etnográficos de su trabajo, los que develan sus referencias políticas y éticas con respecto a la sociedad e historia chilena de esa época. Finalmente, el tercer y último eje analiza su cuerpo de obra en un contexto social, político y cultural clave del arte chileno de mediados del siglo xx donde se sitúa su producción artística.

Gran parte de su obra se encuentra en importantes colecciones privadas en Chile y en el extranjero, como también expuesta en algunas reparticiones públicas, como embajadas y municipalidades ${ }^{2}$. Realizó una extensa labor docente, escribiendo

* Universidad Católica de Temuco.E-mail: lvillegas@uct.cl.

** Universidad Católica de Temuco.E-mail: rvaccaro@uct.cl.

*** Universidad Católica de Temuco.E-mail: amelladol@uct.cl.

${ }^{1}$ Nota aclaratoria: Los términos propios de la lengua mapuche mapuzungun que aparecen aquí registrados están escritos según consta en las fuentes originales. Al ser estas variadas, se entrecruzan las versiones escritas por la misma Celia Leyton con las de la prensa local y otras fuentes utilizadas por el equipo de investigadores. Por ello, una misma palabra propia del mapudungun, puede aparecer aquí escrita de distinto modo, dependiendo de la fuente citada específicamente.

${ }^{2}$ La obra pictórica de Celia Leyton está bastante dispersa, debido a que sus obras han sido donadas, vendidas y puestas en comodato. En primera instancia se han identificado dos colecciones privadas con pinturas y bocetos de la artista. Otras obras se encuentran en el Regimiento de Montaña n. 8 Tucapel de Temuco, Liceo Gabriela Mistral de Temuco, Pinacoteca de la Universidad de 
diversos artículos y dos libros (Araucanía, rostro de una raza altiva y Rupandungú). En términos generales, su prolífica labor artística fue coronada con la fundación de la Academia de Bellas Artes de Temuco. Otros hitos importantes fueron los viajes y exposiciones fuera del país; entre estas últimas se destacan las realizadas en las ciudades de Madrid y Cuenca, en España. También su nombre ha sido reconocido en diversos ámbitos culturales de Chile, siendo uno de los más relevantes su nominación como «Mujer Bicentenario» ${ }^{3}$.

\section{ACERCA DE SU BIOGRAFÍA}

En un principio, su formación artística la realizó en la Escuela Técnica Femenina en Santiago de Chile, donde tuvo como profesores de dibujo y pintura a Nicanor González Méndez y Pedro Rezka Moreau ${ }^{4}$. Posteriormente, ingresó a la Escuela de Bellas Artes en Santiago, donde tuvo como maestros de pintura y dibujo a Ricardo Richon Brunet ${ }^{5}$, Juan Francisco González ${ }^{6}$ y Alberto Valenzuela Llanos . Como ella misma relata

Bueno, llegué por fin al anhelado aprendizaje de la pintura, no a Bellas Artes, sino a la escuela Técnica Femenina, donde el profesor de dibujo y de pintura era

Concepción, Museo Histórico Gabriel González Videla y en el Museo Regional de La Araucanía, perteneciente al Servicio Nacional del Patrimonio Cultural, entre las que se tiene registro.

${ }^{3}$ La denominación a Mujeres Bicentenarias tenía como objetivo destacar el aporte de mujeres en distintos ámbitos del quehacer nacional en pos de la construcción de Chile del Bicentenario y que no fueron reconocidas en la historia reciente del país. Fuente: http://www.bicentenarias.cl/ms celia_leyton.htm.

${ }^{4}$ Pedro Rezska Moreau (1872-1960). Pintor chileno. Fue alumno de Pedro Lira, Juan Francisco González y Cosme San Martín. Con una importante carrera desarrollada en Francia, retorna a Chile en 1914, donde se dedicó por completo a la docencia. Fundador de la Sociedad Nacional de Bellas Artes en 1918. En 1947 obtuvo el Premio Nacional de Arte. Fuente: https:/www.artistasvisualeschilenos.cl/658/w3-article-39905.html.

5 Ricardo Richon Brunet (París 1866-Santiago de Chile 1946). Artista visual francés, de gran relevancia en el medio europeo de la época, recibió premiaciones y reconocimientos en Francia, EE. UU., España y Rusia. Fue profesor de pintura en la Escuela de Bellas Artes de Chile, llegando a ser su subdirector. Recibió importantes encargos del Estado de Chile, como, por ejemplo, su nombramiento como secretario general de la Exposición Internacional realizada en el Palacio de Bellas Artes, en el contexto de la celebración del Centenario de la Independencia de Chile. Fuente: http:// www.artistasvisualeschilenos.cl/658/w3-article-40028.html.

${ }^{6}$ Juan Francisco González Escobar (1853-1933). Pintor chileno. Fue alumno de Alessandro Cicarelli y Pedro Lira. Profesor por más de 30 años de las cátedras de Croquis y Dibujo al Natural en la Escuela de Bellas Artes. Es reconocido como uno de los pintores más importantes en la historia del arte chileno. Fuente: https://www.artistasvisualeschilenos.cl/658/w3-article-78055.html.

7 Alberto Valenzuela Llanos (1869-1925). Pintor chileno. Fue alumno de Cosme San Martín, Pedro Lira y Juan Mochi. Becado cuatro veces para estudiar pintura en Francia, logró la cátedra de Pintura en la Escuela de Bellas Artes en 1911. Junto con recibir innumerables premios y distinciones, obtuvo la Cruz de Caballero de la Legión de Honor, otorgada por el Gobierno francés. Fuente: https://www.artistasvisualeschilenos.cl/658/w3-article-40032.html. 
don Nicanor González Méndez, artista de renombre; establecimiento donde no habían jóvenes.

Dos o tres ańos transcurrieron dibujando solamente -era un gran dibujante González Méndez-, pero yo ardía en deseos de pintar y por ello me resultaba monótono el copiar y pintar los modelitos de yeso (Leyton 1968).

En los inicios de su carrera, la ansiedad por comenzar a pintar era inmensa, inquietud que fue de algún modo aplacada por las formas de enseñanza de las artes de la época. Estas clases consistían principalmente en la copia sistemática de modelos de yeso. Esta modalidad de aprendizaje académico le produjo en cierto modo una frustración al no poder expresarse libremente en sus primeras creaciones. Posteriormente ingresó un nuevo profesor de dibujo, Pedro Reszka, quien le permitió tener una mirada distinta acerca del arte.

Un nuevo profesor de dibujo para los cursos de moda, don Pedro Reszka. Llegué hasta él pues había visto reproducciones magníficas de sus pinturas y también había leído algo de su interesante personalidad.

Con la caballerosidad que le distinguía, inmediatamente me acompañó a ver mi estudio que en esta ocasión era un grupo de diferentes frutas en una tela de $70 \times$ $50 \mathrm{~cm}$. El señor Reszka se sentó frente al cuadro y a la vez que daba explicaciones daba manotazos en el cuadro y toda la pintura de los tubos se le hacía poca para desparramarla para acá y para allá.

Frenética reprobación de mis compañeras por haber deteriorado el lindo cuadro y felicidad completa para mí, pues entonces empecé a deslumbrar lo que era el arte (Leyton 1968).

El trabajo que Celia Leyton realizó en ese entonces fortaleció su formación, ejecutando varios estudios que le permitieron visualizar sus habilidades artísticas y convencerse a sí misma de que debía ingresar a la Escuela de Bellas Artes, lo que se hizo efectivo en el año 1908.

Por fin llegué a la Escuela de Bellas Artes gracias a la intervención ante papá de unos primos sumamente católicos. Cumplida mi gran ambición.

En primer año, estudios de estatuas con el gentilísimo francés don Ricardo Richon Brunet $[\ldots]$

Dos años transcurrieron antes de llegar a la clase de don Juan Francisco González, a quien adoraba desde lejos; pero una vez ante él le tuve terror. [...] en el curso de croquis donde en un minuto se debía realizar por lo menos cinco croquis grandes ¡que decir!, este maestro era de un dinamismo asombroso (Leyton 1968).

Al cabo de unos años de rígida formación plástica, decidió abandonar la Escuela de Bellas Artes para dedicarse a la docencia en la educación primaria. Su primer trabajo en este ámbito estuvo en el Liceo de Niñas de Concepción, ciudad ubicada a $270 \mathrm{~km}$ al norte de Temuco. Luego de un par de años se trasladó a trabajar en el Liceo de Niñas de Temuco, donde se desempeñó desde el año 1931 al 1956, desarrollando en casi 25 ańos gran parte de su carrera como artista visual y profesora de arte. 
En términos generales, la mirada que Celia Leyton tuvo sobre el arte y la cultura está determinada en algunos aspectos por su propia formación académica en la pintura y el dibujo, así como también por su acervo cultural, influenciado por los discursos historicistas y socioculturales imperantes en la época. Sin embargo, su trabajo deja develar otros rasgos que posibilitan su situación como una artista representativa de una época y contexto en la historia del arte chileno, desarrollado en este caso en los márgenes de la oficialidad y el centralismo metropolitano. Ello se puede deducir del radio de acción restringido a lo local que marcó su trayectoria artística como docente y como pintora, que determinó su interés exploratorio e intercultural en una región aún fuertemente marcada por "La Frontera»" situada en la periferia de la influencia capitalina. Ello la mantuvo fuera de los circuitos santiaguinos, a pesar de haber obtenido varios reconocimientos y premiaciones en los concursos oficiales?.

\section{EN TORNO A SU PINTURA INDIGENISTA}

Si bien Celia Leyton se perfila como una de las principales representantes del arte indigenista en Chile, para comprender cómo ella desarrolló y proyectó su obra artística, es necesario visualizar el contexto latinoamericano y cómo esas ideas permearon de distinto modo su propia obra. El movimiento indigenista se vio influenciado por las ideas de reivindicación de los derechos indígenas que nacen de modo posterior a la Revolución Mexicana iniciada en 1910. Estas ideas impactaron progresivamente los ámbitos culturales, intelectuales y artísticos de gran parte de América Latina, contexto del cual Chile no estuvo ajeno. Desde esta perspectiva, el escenario social y político entre 1920 y 1930 influye con más o menos fuerza en el plano de las ideas estéticas, lo que activa la generación de varios movimientos artísticos que tuvieron asidero en las demandas y planteamientos sociales, reforzando la idea de la urgencia de una búsqueda o redescubrimiento de una identidad estética americanista. Uno de los movimientos más reconocidos de esta corriente indigenista es el muralismo mexicano, donde a través de su manifiesto, David Alfaro

${ }^{8}$ El concepto de «La Frontera» se gesta en Chile durante la denominada Guerra de Arauco, a partir de la segunda mitad del siglo xvir. La Frontera se sitúa en el sur de Chile, zona que sufre una serie de transformaciones que la convirtieron en un espacio de interacción, roces, conquista, guerra, ocupación e intercambios comerciales y culturales entre indígenas y espańoles. Este territorio se convirtió en un espacio de convivencia entre distintos actores, que por una parte representaban los intereses de la Corona y por otro los intereses de las distintas comunidades indígenas mapuches que ahí estaban establecidas (Ferrando 2012).

9 Entre sus principales premiaciones se pueden destacar la Medalla de Oro en la Escuela de Bellas Artes (1922), Medalla de Oro en la exposición de Pinturas de Concepción (1925), primer premio en la semana Penquista (1927), primer premio Exposición de Concepción (1929), Tercera Medalla en el Salón Nacional de Bellas Artes (1941), Medalla de Bronce en Salón Nacional. Homenaje a Maestros de Virgilio Arias Cruz y Enrique Swinburnkirk (1942), Medalla de Oro Municipalidad de Temuco (1948), Medalla de Plata Municipalidad de Temuco (1948) (Diario Austral 1950). 
Siqueiros da cuenta de esta lucha por la reivindicación de los derechos de los pueblos indígenas, utilizando como un medio y estrategia de representación la pintura mural para promover las ideas de educación, organización y cultura de masas. Sin embargo, en Chile este medio de difusión visual y político no tomó la fuerza que en otros países del continente.

... primero David Alfaro Siqueiros y Xavier Guerrero, en los murales de la Escuela México de Chillán y, luego Jorge González Camera, en Concepción generan argumentos y entusiasmos frente a una expresión artística hasta ese momento de presencia bastante menguada en el país. La posibilidad de dar una connotación de masividad a un texto estético, imbricado las más de las veces con un discurso social, permite un escalamiento no poco significativo de la pintura mural en el país, ello especialmente en la década de los años cuarenta al sesenta. Con todo, el muralismo en el país tiene una presencia puntual y muy acotada en el panorama de las artes visuales. Quizá haya faltado aquí la fuerza de la sangre, para transformar a esta interesante expresión artística en un fenómeno más trascendente en nuestro discurso estético (Zamorano y Cortés 2007).

Es en este contexto en el que en el año 1952, el Supremo Gobierno de Chile le solicitó a Celia Leyton la realización de un mural emplazado en dependencias del ex Liceo de Niñas de Temuco, actualmente Liceo Gabriela Mistral. Este encargo fue un reconocimiento a la labor creativa de la artista, cuyo tema central es el homenaje al primer profesor mapuche, Manuel Neculmán. Este educador, hijo de un longko ${ }^{10}$ de una comunidad indígena del sector de Boroa, localidad cercana a Temuco, representa el sentido y relevancia histórica que Celia Leyton le atribuye a la reeducación cultural y social de los hijos de los líderes mapuches (Foerster \& Montecino 1988).

El mural del edificio de Correos y Telégrafos de Chile ubicado en Temuco, actualmente oficina de Correos de Chile, es el segundo encargo en este formato que la artista lega a la comunidad local. La composición visual describe una escena del mundo mapuche: el huerkén (mensajero) le entrega un mensaje al «jefe de paz» Üllmen, el cual está registrado en una larga cuerda anudada (quipu). La misma Celia Leyton al referirse al contenido de este mural utilizó el término pron para describir este sistema de comunicación a larga distancia, cuyo instrumento es la cuerda anudada. Junto con la escena propiamente tal, están representados a modo descriptivo algunos objetos de alto valor cosmogónico, como el kultrun ${ }^{11}$, lanzas, piedras talladas, rewe $e^{12}$, entre otras. Este mural, de 2,80 × 5,75 metros, se encuentra en el

${ }^{10}$ Longko o cacique es el jefe o la autoridad de la comunidad mapuche. Está a cargo de los aspectos políticos, administrativos y religiosos de esta misma.

${ }_{11}$ Instrumento de percusión consistente en una vasija de madera cubierta de cuero (chivo o caballo). Tiene diversas funciones sociales; la más relevante es servir a la machi en sus ceremonias. También tiene un carácter simbólico y representativo (Hernández et al. 2002).

12 Tronco descortezado de árbol, labrado con peldańos (laurel, maqui, canelo), enterrado frente a la puerta de la ruka de la machi, de la cual es instrumento y símbolo. En algunos lugares y 
frontis superior de la sala principal del edificio, a una altura considerable y con una perspectiva de apreciación privilegiada, hasta el día de hoy (El Diario Austral 1962).

Celia Leyton centró su obra en la promoción de las costumbres y tradiciones del pueblo mapuche, a través de la cual realizó un riguroso ejercicio etnográfico creando retratos, escenas costumbristas y rituales que dan cuenta de aspectos cotidianos y de la cosmovisión de este pueblo. Este trabajo lo llevó a cabo mediante su constante contacto con personajes de diversas comunidades indígenas rurales aledañas a Temuco y otras comunas de la región, a las cuales ella viajaba para bocetear y pintar in situ escenas que los lugareños le permitieran plasmar. Este trabajo lo realizó por muchos años, ganándose la confianza de las comunidades indígenas y así poder ser testigo presencial de importantes ceremonias y rituales propios de la cosmovisión mapuche, que logró recrear en algunas de sus telas.

Es Celia Leyton un Diego de Rivera chileno. No porque lo haya imitado, ni porque pretenda realizar lo autóctono en la misma forma que el gran mexicano. No. La semejanza está en la ardorosa intención de entregarnos el mensaje del espíritu autóctono y los valores de una cultura enraizada, quierámoslo o no, en las entrańas de nuestro vivir actual.

La clase culta de todos los países latinoamericanos ha exaltado su ascendencia europea, española sobre todo. Y arroja una desdeńosa mirada a los abuelos autóctonos. La atención y aprecio que se dedica a Diego Rivera son resultados indirectos de las críticas mundiales que ya lo han consagrado como un valor eminente y sin par en las artes pictóricas americanas. Temo que pasen años antes que se le prodigue una migaja de gloria a esta mujer que hace de la humilde vida de las gentes araucanas el leitmotiv de su producción artística. A la vez, estoy cierta de que el futuro la elevará a un sitio de honra ejemplar y única (Labarca en Leyton 1968).

Su producción ha incorporado distintos lenguajes pictóricos, en los cuales utilizó diferentes soportes y formatos, como la pintura de caballete y la pintura mural. En un primer período de su formación, se abocó a los estudios tanto de obras maestras como de bodegones y paisajes naturales, estrategia que era muy utilizada en la academia. Esos ejercicios y obras los realizó en acuarela, pastel, óleo y la compleja técnica del fresco, con la que pintó los murales. Posteriormente, se centró en realizar escenas costumbristas y retratos de la cultura mapuche. Son variadas las fuentes que dan cuenta de la importancia que para ella tuvo este tipo de representación, principalmente en sus escritos autobiográficos, así como en la prensa local de la época.

Esa es la verdad, Celia Leyton lleva largos ańos batallando en el ambiente temuquense y regional para imponer su pintura, pero se encuentra con el desdén de mucha gente que no quiere nada con temas indios. El desprecio por el aborigen suele llegar hasta más allá de lo comprensible, hasta incluso odiar las expresiones artísticas que giran en torno a lo vernáculo. De la siempre activa virulencia de este

ocasiones es también una especie de pabellón o símbolo representativo de una determinada comunidad (Hernández et al. 2002). 
complejo, Celia Leyton recibe su cuota de sinsabores. Pero se sobrepone y sigue sin merma realizando su obra. No ha trepidado en sacrificios para cumplir su propósito, ha editado dos libros con la relación pictórica y literaria de la vivencia aborigen y ambos le han dejado pérdidas económicas (Leyton 1968).

Fueron muchos los sacrificios económicos y de vida que realizó la artista para llevar a cabo lo que ella determinó como «su labor». Así lo expresó Juan Francisco González (hijo), quien utilizaba el seudónimo de Huelen, reconocido crítico de arte en diversos medios escritos de la época.

Su pintura es la misma, la de su personalidad, pero ahora más luminosa y firme, con mayor sentido de la composición y de esa amplitud de temas que acusa un temperamento incansable, pleno de ansia de pintar, y de pintar para satisfacer esa sed inagotable que sigue y persigue al artista de verdad, cabezas admirables, flores luminosas, y más que todo el tema de su pasión, el indio en su fisonomía austera y grave y en sus costumbres y escenas típicas nos rodean en su taller (Huelen 1956).

\section{INSPIRACIÓN INDIGENISTA EN CELIA LEYTON}

Cuando nace Celia Leyton, en 1895, apenas acababa de concluir en el sur de Chile la llamada "Pacificación de la Araucanía», que consistió en términos generales en el desarrollo y culminación de un proceso político y jurídico empeñado en la reubicación de las comunidades indígenas, despojándolas consiguientemente de la mayoría de sus territorios. Tal como lo analiza Vargas en el artículo «Los aportes de Claude Joseph sobre el mundo mapuche: Cultura material y fotografía del Museo Histórico Nacional ${ }^{13}$, de aproximadamente cinco millones de hectáreas que poseían originalmente las comunidades mapuche, hacia el año 1883 les quedaban no más allá de 500000 (Vargas 2019).

Fue la artista una testigo de primera línea de este proceso que significó la desintegración de la vida mapuche, la pérdida de sus derechos, el robo y la usurpación de sus territorios, su consiguiente empobrecimiento, hambrunas y epidemias.

El panorama no era muy auspicioso para este pueblo. Tal como indica también Vargas (2019), existía un claro consenso entre las voces más expertas en el tema de la cultura mapuche en cuanto a que su destino era prácticamente una condena a la desaparición. En términos generales, una cultura empobrecida que termina siendo absorbida por la cultura dominante; en este caso, la chilena. El autor men-

13 «[...] El texto problematiza ambas dimensiones a partir tanto del término "cultura material" como de los estudios etnográficos del autor, recurriendo para ello a fotografías, textos y dibujos originales de su autoría depositados en el Museo Histórico Nacional. Se sostiene que Joseph aportó a la conformación de un campo de estudio del arte mapuche que contribuye a dar cuenta de la heterogeneidad cultural de este pueblo. Asimismo, se plantea que su producción fotográfica fue relevante para la instauración de ciertos imaginarios y que sus investigaciones colaboraron a la revitalización de la mencionada cultura» (Vargas 2019). 
ciona a importantes investigadores de esa época como Félix de Augusta (1910), quien entrega un claro diagnóstico: «La raza araucana pasa hoy por un período de transformación. Lo que nuestra obra refiere acerca de sus costumbres y supersticiones, dentro de poco ya no corresponderá a la realidad, ni se guardará memoria de ello» (p. vi) (De Augusta en Vargas 2019). No es de extrañar que los empeños de Celia Leyton respecto a una ética del arte consistieran en "rescatar» $\mathrm{y}$ «salvar del olvido» a los valores de la cultura ancestral.

Celia Leyton fijó su horizonte productivo en la urgencia de la valoración de lo mapuche, a través de la ejecución de paisajes y retratos de distintos personajes, algunos de alto rango social, como machis ${ }^{14}$, longkos o comerciantes, como también profesores y gente a veces anónima, que poblaron el imaginario de la artista. Existe numerosa documentación que permite observar el perfil de Celia Leyton como productora de imagen visual, pero también como investigadora en terreno, prácticas que hoy podríamos identificar como etnográficas. La búsqueda de la artista en su trabajo de ningún modo describe de forma literal los usos y costumbres mapuche, sino que definitivamente intenta escudrińar en los aspectos psicológicos y/o espirituales que «iluminan» la cultura.

Diecisiete años que vivo en Temuco. Temuco diríase es el centro de esta raza que otrora fuera fuerte y valerosa y que aun conserva casi intactas sus virtudes. Siempre me sedujo el típico y vistoso atavío de las mujeres araucanas y medité largamente sobre las costumbres del pueblo que nos sirvió de piedra angular para la formación de la propia raza. Sin embargo, no pinté inmediatamente. Primero investigué y pronto me convencí de que la enseñanza recibida por mí respecto a los mapuches era falsa en gran parte. Se ha mentido mucho acerca de los indios. Lo puedo decir con entereza. Se ha especulado con su flojera. No hay tal. La araucana es una raza que sufre resignadamente su suerte, pero que trabaja duramente. El hambre no le hace doblegar la cabeza. Su gente físicamente es magnífica, recia y fuerte. Muchos son los que piensan superficialmente que los mapuches son feos, flojos y borrachos y que deben desaparecer, sin darse el trabajo de pensar que sería más humanos crearles ambiciones de comodidades y de cultura y tratar de inculcarles confianza para que ingresen a la ciudadanía del país con iguales derechos que el «huinca» (El Diario Austral 1950a).

Este contexto de invisibilización y desprecio por las culturas indígenas por parte de la sociedad chilena de esa época complejizó enormemente la función que para ella tenía el arte. Su temprana formación académica en Santiago le permitió conocer los fundamentos del género del retrato en la tradición renacentista y moderna de la pintura. Sin embargo, fue evidente su rebeldía constante frente a las imposiciones del patriarcal mundo del arte y la cultura que ella debió enfrentar.

${ }^{14}$ Persona elegida por un espíritu superior para asumir el papel de médico tanto en lo físico como en lo psíquico y social. En algunos sectores es también oficiante principal en el ngillatun (Hernández et al. 2002). 
«Era de rigor agudizar mis pésimas condiciones de sociabilidad; debía ocultar mi cansancio, a veces mi descontento; sólo así podía obtener confidencias, relatos que encuentro en mis borradores...» (Leyton 1968). De este modo, Celia Leyton grafica su enorme empeño en conocer las prácticas culturales, creencias, cosmovisión, psicología y usos del pueblo mapuche, que luego decantaron en su producción

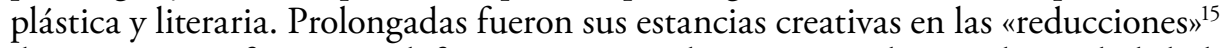
de Quepe, Pitrufquén, Carilafquén, Lautaro, Isla Huapi, Huilio, Maihue, Chol chol, Budi, Carahue, entre otras localidades de la región de La Araucanía.

Su paso por las ferias, exposiciones en hoteles y otras instancias de difusión de su obra estuvo cargado de sinsabores, menosprecio y omisiones que, sin embargo, no debilitaron su intención férrea de impulsar su carrera artística con un fin particular, humano y ético. Su trabajo fue postergado y negado en los estratos altos de la sociedad temuquense. En ciertos momentos, ya vencida por el cansancio de la incomprensión y falta de empatía del «circuito intelectual del arte» por su proyecto artístico, planeó abandonar la enseñanza primaria, suspender algunas de sus relaciones familiares directas, abandonar sus comodidades y sumergirse en la investigación en terreno, para así proyectar su visión del arte y la cultura mapuche, aspectos que de a poco se van amalgamando en un concepto de trabajo único y particular en ella. En este sentido, la artista no acostumbraba a deshacerse de sus bocetos, pues estos guardan la vibración esencial de los lugares y las personas.

Mujer de pocas palabras, según ella misma con pocas habilidades comunicativas, extremadamente tenaz, decidida, valiente a toda prueba, rebelde. De profunda vocación intercultural, amor por la divulgación y la docencia, aunque con profundos conflictos con los contenidos y metodologías establecidos en los programas del Ministerio de Educación.

Tempranamente, la crítica local emitirá los primeros juicios sobre su trabajo pictórico, alabándolo públicamente, destacando el conocimiento que la autora construyó como investigadora y artista, siendo sus pinturas una especie de documentos etnográficos que dan cuenta de características culturales de la cosmovisión mapuche, tanto en sus expresiones materiales como también en el estudio psicológico que enfrentó a través de su extensa obra retratística.

Esta modernidad temprana reprodujo la inspiración eurocentrista que le dio origen en el siglo xIx a la ciudad de Temuco e inspiró a sus habitantes. Sin duda este modo de visualizar el progreso de una nación tuvo su raíz en el proyecto nacionalista que se afianzó en el contexto de la celebración del centenario del país, momento en que surgieron profundas tensiones respecto de lo que significó el «ser chileno». Este afianzamiento de la chilenidad de ningún modo consideraba el valor concreto de los pueblos ancestrales, los cuales se invisibilizaron notoriamente en todo contexto de la vida cotidiana. El proyecto modernizador de Temuco se ve, hasta el día

15 El término reducciones hace alusión al proceso de reducción territorial del pueblo mapuche por parte del Estado chileno, que los agrupó de forma arbitraria en pequeños espacios territoriales muy distintos a los que ellos utilizaban tradicionalmente (Ferrando 2012). 
de hoy, constatado en la proyección arquitectónica que se debió impulsar luego del gran incendio de la ciudad, ocurrido el año 1908, que obligó un complejo proceso de recostrucción y rediseño urbano de la ciudad. Este programa estuvo inspirado en los paradigmas neoclásicos instalados por Benjamín Vicuña Mackenna ${ }^{16}$ para el proyecto urbanista de la ciudad de Santiago de Chile, mientras fue intendente de la capital entre 1872 y 1875.

Escasamente, se visualiza en los medios de comunicación de la época el interés en instalar públicamente la discusión respecto del valor e importancia de la cultura mapuche en la construcción de la identidad nacional. Sin embargo, destacan algunas iniciativas que surgen del ámbito público, como lo es en 1952 la instancia de cooperación entre las gobernaciones de Cautín y Malleco ${ }^{17}$ para coordinar a través de un comité ad hoc la creación de un monumento a La Araucanía, con el objeto de llevar a la realidad un viejo anhelo en «homenaje a la raza Araucana, cuyas grandes gestas honran las páginas de la historia de Chile» (El Diario Austral 1952). Este monumento se pretendía realizar en piedra o bronce y sería financiado a través de una colecta nacional que reuniría los fondos necesarios para su ejecución. Dicho monumento jamás fue llevado a cabo.

\section{SU PRODUCCIÓN INTELECTUAL}

No solamente óleos, dibujos y frescos emergieron de la mano de Celia Leyton; una de las características que destacaron en el trabajo de esta artista fue la capacidad que tuvo de producir textos que dieran cuenta de sus procesos reflexivos y creativos. Su capacidad de gestión le permitió contar con el apoyo de connotados intelectuales y críticos de arte de la época, que escribieron acerca de su producción.

En cada uno de sus textos cuenta con imágenes que, acompañadas de relatos descriptivos, dan cuenta del contexto y los personajes que constituyen parte central de ellas. Víctor Camacho, pintor y crítico de arte, consigna que «la pintura de Celia Leyton tiene el significado de un comienzo por incorporar a la pintura chilena un trozo de su personalidad nacional. Lo araucano no es sólo un tema más de colorido pictórico, sino un aspecto insospechado que linda con lo más genuino de nuestro espíritu» (Leyton 1968).

Entre sus textos destaca Araucanía, rostros de una raza altiva, realizado en 1945, libro-catálogo que hace referencia a su producción visual y pensamientos e ideas que de su experiencia investigativa han decantado en el documento impreso. Este libro, que incluyó ilustraciones a color, se agotó rápidamente (Cortés 1953), lo que la obligó a producir una nueva edición en 1953.

16 Benjamín Vicuña Mackenna (1831-1886). Escritor, periodista, político e historiador chileno. Americanista y defensor de la modernidad, fue responsable de variados planes de modernización urbana en la capital y otras ciudades de Chile. Fuente: http://www.memoriachilena.gob. $\mathrm{cl} / 602 / \mathrm{w} 3$-article-561.html.

${ }^{17}$ Cautín y Malleco son las dos provincias que componen la Región de La Araucanía. 
Por otra parte, Rupandungú es su producción más extensa y donde se registran los datos biográficos más importantes junto a sus impresiones, relatos y análisis. Fue editado por ella misma en el año 1968 e impreso por Editorial Universitaria en Santiago de Chile. Básicamente un texto autobiográfico, Rupandungú según la autora significa hechos pasados, de ahí su aproximación lingüística al concepto propio del mapudüngun ${ }^{18}$. Este proyecto no buscó ensalzar el propio nombre, ni reforzar su propia identidad, ni dejar elementos de su universo personal dispuestos a la trascendencia. Según plantea la misma autora, este libro debía operar como un dispositivo que acercara a las personas al mundo y al valor de la cosmovisión mapuche. Concretamente, Celia Leyton indicó que su obra pictórica tiene una utilidad central que es servir de puente afectivo con el mundo mapuche, para poder devolverle un valor perdido por la historia de abusos acaecidos. Otro dato interesante en esta producción anexa a su trabajo plástico visual es que está creado de modo tardío a la data de la mayoría de los hechos ahí descritos, por lo que es una creación que surge desde la "memoria» propiamente tal, lo que sin duda idealiza algunos pasajes y situaciones experimentadas.

El prólogo de Rupandungú fue escrito por Amanda Labarca, distinguida académica de la época, con un muy alto perfil público de intelectual activista, siendo ella una de las precursoras del feminismo latinoamericano. Amanda Labarca y Celia Leyton pertenecieron a una misma generación, y por lo mismo compartieron similares retos. Ambas impulsaron sus carreras como un modo de reaccionar contra el profundo tradicionalismo patriarcal que guiaba el sentido de numerosas familias chilenas en ese entonces.

No ha habido rey que sujetase esta soberbia gente, libertada, ni extranjera nación que se jactase, de haber dado a sus términos pisada. $\mathrm{Ni}$ comarcana tierra que se osase mover en contra y levantar espada siempre fue exenta, indómita, temida, de leyes libre, y de cerviz erguida (Ercilla en Leyton 1968).

Con esta cita del canto primero de La Araucana, obra poética cumbre de Alonso de Ercilla ${ }^{19}$, da inicio a este relato, simple en su conceptualización y profundamente dinámico y transparente en su redacción, dando cuenta de sus fuentes de inspiración, sus inicios en el arte, la docencia, su paso por la academia chilena,

${ }_{18}$ Lengua tradicional de la cultura mapuche (De Augusta 2017).

19 Alonso de Ercilla y Zúńiga (Madrid 1533-Toledo 1594). Soldado, poeta e historiador español. Permaneció 17 meses en el sur de Chile como efectivo militar en la Guerra de Arauco. En esta época escribió el poema épico La Araucana, obra considerada fundacional en el imaginario literario y poético chileno. http://www.memoriachilena.gob.cl/602/w3-article-3285.html. 
exposiciones, viajes y su intensa experiencia en el campo de la pintura mural, entre otros aspectos de su agitada vida como promotora y gestora cultural.

En 1950 produjo algunos textos-catálogos de su obra Raza Araucana, 8 pinturas de Celia Leyton, que contienen imágenes y pequeños textos introductorios. Estas publicaciones de divulgación fueron creadas por Celia Leyton para ser estudiadas por los niños, con el afán de entregar una visión objetiva y descriptiva de las características de la cultura mapuche, entendida como una base fundamental de conocimiento para la formación escolar chilena. En este mismo sentido, algunos de los textos fueron traducidos al inglés y al francés, para así facilitar su difusión fuera del país.

\section{EN TORNO A SU OBRA}

Sin duda un aspecto fundamental en la trascendencia de la obra de Celia Leyton hace relación con las distintas fases de desarrollo de su planteamiento estilístico, o mejor dicho, el modo en que ella va comprendiendo las complejas relaciones entre estilo, técnica y estética con que se enfrenta la pintura moderna. Sin duda, las metodologías académicas que conoció y experimentó desde el inicio de su formación pictórica fueron influyendo positivamente en su visión artística.

Celia Leyton tuvo oportunidad de ser formada por maestros provenientes del sistema academicista, pero que, sin duda, a esas alturas ya eran considerados referentes fundamentales para la pintura moderna y vanguardista chilena. Pedro Rezka Moreau influyó profundamente en el modo de pintar de Celia Leyton. En Rupandungú la autora lo recuerda con esta frase: "¿Y eso qué? Se puede dar diez, veinte, treinta y más sesiones; la importancia está en preparar bien, saber la calidad del empaste cada vez que se pinta, y dibujar pintando» (Leyton 1968).

«Dibujar pintando»... Visiblemente esta declaración orienta su planteamiento técnico plástico, el cual desde lo intuido se aproxima a una concepción crítica de la representación visual que se aleja del antiguo procedimiento canónico inspirado en la declaración "pintar lo que se sabe del objeto», para así transitar a la idea de pintar «lo que se ve» del objeto. Esta noción del arte visual surge de la revolución pictórica iniciada en Francia por Édouard Manet, quien dio pie al desarrollo del movimiento impresionista, con toda la revolución técnica, procedimental y conceptual de la pintura que, a estas alturas, ya contaba con un respaldo medianamente oficial en los círculos pictóricos. Evidentemente en el tardío circuito regional chileno, esta manera de entender la pintura no va en la misma línea proyectiva del arte oficial en la academia chilena de principios de siglo.

Todo este relato de esfuerzo de taller se ve ensombrecido por un episodio violento por parte del pintor Juan Francisco González; al parecer, con gritos e improperios destruyó un estudio que realizaba Celia Leyton en su taller. "¿Se ha creído Ud. que mi tiempo no vale, al perder mis enseńanzas, pintando cosas estúpidas, mamarrachos? No pedí perdón, porque habría sido contraproducente, pero mi arrepentimiento fue sincero» (Leyton 1968). Ella escribe con antiguo dolor en sus memorias. En esos mismos pasajes donde recuerda la amarga escena con su maes- 
tro, concluye que quizás por esta razón no estuvo entre las seleccionadas para obtener una beca de estudio en París.

El proyecto estético-simbólico de Celia Leyton es destacado por los medios de la época por el alto carácter promotor y de difusión de los valores culturales mapuches, interés que trascendió las fronteras nacionales. Celia Leyton emprendió proyectos de promoción internacional de su obra, cuyos esfuerzos sin embargo no siempre fueron exitosos. La gestión de sus exposiciones fue realizada generalmente de modo autónomo, donde aspectos como el financiamiento para los viajes, o los mismos trámites aduaneros a veces, le jugaron una mala pasada. "Trámites aduaneros argentinos me impidieron 'ventear' a mis mapuches en Buenos Aires". Celia Leyton sólo pudo exhibir 6 telas» (El Diario Austral 1950b) de treinta y tres que ella tenía considerado exponer.

La inspiración indigenista, sensibilidad estética, simbólica y política que condiciona gran parte de la producción de arte vanguardista latinoamericano no fue ajena a los intereses de Celia Leyton. Sus primeros trabajos de estudio se desarrollaron durante dos meses en un taller ambientado como $r u c a^{20}$, en la localidad de Chol Chol, comuna cercana a Temuco. Estas sesiones de taller eran con modelos remunerados, lo que de alguna manera obligó a Celia Leyton a intentar distintas estrategias de diálogo intercultural para poder fijar los marcos de negociación que le permitieran contar con modelos mapuches. Según ella misma relata, es el lenguaje universal de la creación artística el que sirvió como espacio común en el cual surge el encuentro con la otra cultura, un espacio de confianza donde la dignidad, la honestidad y sobre todo el respeto sirvieron para establecer un programa de trabajo creativo donde, a fin de cuentas, lo pictórico se transforma en el medio para acceder a una cosmovisión para ella casi desconocida y por sobre todo fascinante.

Ya la suerte está echada y aquí observamos los cimientos del proyecto estético-político de Celia Leyton. Uno de sus objetivos más añorados en el plano de la difusión de su obra era que el Museo Araucano de Temuco adquiriera algunos de sus cuadros. Luego del reconocimiento público que le diera David Alfaro Siqueiros, en una exposición en Santiago, la Ilustre Municipalidad de Temuco decretó dos mil pesos para adquirir una pintura de Celia Leyton para estos fines. No obstante, fue prácticamente obligada a negociar la entrega de dos obras por este mismo precio. Sin embargo, como si fuera poco, luego la Municipalidad, en sesión edilicia, decretó dejar sin efecto la adquisición, ocupando entonces este dinero en la compra de dos vacas.

«Hay todavía en Temuco muchos mapuches, no tienen importancia los retratos de ellos, ni tampoco los ngnillatunes pintados, asistimos a ellos con frecuencia» (Leyton 1968). Esa era la visión que las autoridades de la época, públicamente y sin pudor, declaraban en su compromiso por hacer de esta una mejor región, una mejor sociedad y cultura. Sin embargo, según relató Celia Leyton, la Municipalidad de

${ }^{20}$ Ruca o ruka es una choza, casa o edificio propio de la cultura mapuche (De Augusta 2017). 
Punta Arenas adquirió estas mismas obras por el doble de la oferta inicial establecida en Temuco.

\section{ANÁLISIS DE LA OBRA AUTORRETRATO DE CELIA LEYTON MILLAKËYÉN}

Generar una propuesta artística desde la cosmovisión mapuche requiere de una reflexión con respecto a la legitimidad del discurso con el cual se enfrenta la dicotomía entre lo representado (cultura mapuche) y quien representa (artista), en un contexto complejo que considera un escenario político, económico y social bajo la perspectiva de la interculturalidad.

El ejercicio del reconocimiento no solo es parte inherente del ser humano, es el «existir» es el yo que se asume diverso, complejo, no siempre, me parece, lúcido en su diversidad íntima y social. Es quizás allí donde se escriben y producen las imágenes de una memoria colectiva que un pueblo puede hacer y las imágenes de una memoria particular que con los aleas y líneas de fuga (personales y colectivas) de la historia resurgen en nuestro pasado y presente.

El reconocimiento sería entonces no solamente un ejercicio para ser sino que también para responder a la pregunta: ¿quien soy? ¿cual es mi retrato? (Chihuailaf 2015).

El autorretrato de Celia Leyton firmando con el seudónimo Millaküyén ${ }^{21}$ se presenta con vestimenta de mujer mapuche, obra que se distingue como portada del catálogo de Raza Araucana, 8 pinturas de Celia Leyton. En este ejercicio plástico, la artista busca situar su imagen (autorretrato) desde una posición de reconocimiento, respeto y pertenencia a la cultura mapuche.

Inicialmente se abordará el análisis de la pintura desde su firma que inscribe el deseo de ser en legitimidad; marca establecida como pseudónimo Millakëyén y que se encuentra como referencia en su libro Rupandungú de la siguiente manera: «Entre mis recuerdos gratos de esos tiempos está aquel en que por primera vez Nanco Catrinao de Carén, me llamó "Millakëyén" nombre que tomé por seudónimo. Me satisfizo su significado, "Luna de oro"” (Leyton 1968).

Esta obra pretende representar una síntesis de los elementos simbólicos y estéticos que logró identificar en las diversas investigaciones en terreno, incorporando en el cuadro su orgullo al portar vestimenta, tejidos, platería y colores de la raza araucana. Celia Leyton Millakëyén en su autorretrato señala los códigos interpretados desde la riqueza (platería) de la naturaleza (simbología) del territorio y cosmovisión mapuche.

${ }^{21}$ Millaküyén firmada en la pintura difiere de Millakëyén mencionada en su libro Rupadungún, que significa «luna de oro», al igual aparece en el catálogo Raza Araucana, 8 pinturas de Celia Leyton, titulada como Millahüyen. 
En el análisis de esta obra se observan distintas áreas que poseen una fuerte carga simbólica y que se representan de manera intensa a través de la práctica pictórica de la artista. La incorporación de tejidos y platería mapuche en la pintura son metáforas y claves para una lectura más amplia del contexto cultural mapuche.

En la imagen pintada destaca la representación de la forma de un trariwe $^{22}$ como centro de interés, tanto por el área que ocupa en la composición como también por la densidad cromática y simbólica que representa. La investigadora Susana Chacana señala:

El trariwe es una prenda altamente significativa dentro del mundo femenino mapuche. La mujer teje para ella y otras mujeres, es un elemento protector, firme y bello, para la fuerza en la cintura y el vientre materno. Protegerse fajándose implica proteger lo interno de posibles males externos, corrige, endereza. Además, este útil elemento otorga información cultural específica sobre la definición y/o valoración de la posición social de quien la lleva (Chacana 2012).

En el trariwe se pueden observar diseños con estructuras antropomorfas y fitomorfas donde destaca el lukutue ${ }^{23}$. Figura que "[...] corresponde a un "personaje ritual asexuado, representación de los participantes de la gran rogativa, Nguillatún". La voz Lukutuel significa "el arrodillado" y se constituiría por desdoblamiento" (Montecinos 1995). En este sentido, Celia Leyton utiliza este diseño simbólico del lukutuel como un elemento central de la composición del retrato, haciendo alusión a la estratificación social de la cultura mapuche.

El trariwe es representado de manera dinámica y descriptiva en sus formas, en la interpretación que hace su pincelada con pigmentos al óleo rojo carmín y blanco, en gestos de color puro y en un dibujo descriptivo. Predomina el uso del color rojo de acuerdo al testimonio de Matilde Painemil: «Tiene que ser rojo oscuro, una forma de trariwe que llevan las mujeres es una forma de proteger, es más para protegerse de la naturaleza, entonces por eso pusieron rojo oscuro, por que el rojo siempre protege de la maldad» (Chacana 2012).

Otro aspecto importante a destacar en su pintura es la incorporación de elementos de la platería tradicional mapuche, que identifican la zona territorial, el estrato social y familiar que la mujer posee dentro de esta cultura.

22 Trariwe o faja de cintura femenina mapuche de alto contenido simbólico, de acuerdo a creencias ancestrales se utiliza como un objeto de protección, el cual es elaborado principalmente por mujeres.

${ }^{23}$ Símbolo antropomorfo que aparece en los diseños textiles realizados en la cultura mapuche, especialmente en la faja femenina denominada trariwe, y que representa un personaje asexuado. En el lukutuel sus partes serían: «Lonko (cabeza), Wisewel (cuerpo), Piuke (corazón) y Puñontrewa (pies y manos semejantes a las huellas de un perro). Esta figura, según está hipótesis, sufrirá una serie de transformaciones a lo largo del tejido de los cuales harán nacer a otras figuras como el Temu (un árbol ligado al poder de las aguas que están en su cercanía, las que dan salud a los recién nacidos que se lavan en ellas) o Rayen, la flor que simboliza la capacidad de fecundación femenina» (Montecinos 1995). 
La platería mapuche es uno de los fenómenos más característicos del desarrollo de la sociedad mapuche y es expresión concreta de su filosofía en estrecha relación con la naturaleza. Y es al mismo tiempo afirmación de opulencia demostrativa de su riqueza económico-ganadera en la que juega el papel fundamental y determinante la mujer mapuche como la poseedora de la continuidad y de la fecundidad de la vida en un plano de igualdad en su küyehtun (ciclo menstrual) con la luna (Painecura 2011).

Otros elementos importantes en la composición de la obra son el keltatuwe (prendedor de plata), el tralilonko (cintillo de cabeza) y los chaway (pendientes de plata), que son parte importante del ajuar femenino mapuche. Celia Leyton en su texto autobiográfico explica que «... Allí supe que el trapelacucha con un cóndor y tres hileras de monedas lo llevan solamente las casadas y que amarrar al trarilonco de plata con un rosetón de cintas blancas significa virginidad» (Leyton 1968). La utilización de artefactos propios del ajuar femenino da cuenta del conocimiento acabado de la autora acerca de estos elementos simbólicos, que, representados con riqueza y dominio técnico, construyen estructuras simples, directas y sobre todo luminosas.

El carácter dialogante de la artista a través de su autorretrato enfatiza la idea de pertenencia a una identidad cultural del pueblo originario, por medio de diversos objetos simbólicos que dan cuenta de una herencia cultural, territorial y de linaje fundamentales para la configuración social del pueblo mapuche.

Junto con su usual firma Celia Leyton Vidal, aparece en el cuadro autorretrato Millekëyen una segunda inscripción como Millakëyén (luna de oro), que contrapone un interés esencial para la artista acerca de su búsqueda identitaria entre ser chilena y ser parte del pueblo mapuche, interrogantes que ella experimentó a diario como artista y como mujer.

El legado pictórico de Celia Leyton no ha sido estudiado desde un punto de vista historiográfico, ni estético, ni formal, por lo que su inscripción en la historia del arte chileno está aún pendiente, reconociéndose su legado en ámbitos aislados y de limitada trascendencia. Causa y efecto es entonces hasta ahora la ausencia de una revisión sistemática de los alcances de su trabajo. Lo anterior podría explicarse por su apropiación de un estilo pictórico muy personal y tardío, anclado en paradigmas postacadémicos, ya superados por la vanguardia chilena de la primera mitad de siglo $\mathrm{xx}$, donde ya está en ese entonces instalada una discusión propiamente teórica sobre los alcances de la ruptura discursiva del arte plástico.

\section{CONCLUSIONES}

Celia Leyton centró su trabajo en retratos, paisajes y escenas costumbristas de la cultura mapuche, que la posicionan como una figura central de la corriente indigenista chilena, la cual fue reconocida por artistas, críticos de arte e intelectuales de la época. Si bien ella tuvo una formación académica como artista, es capaz de incorporar estos elementos en sus obras realizando una síntesis entre la tradición artística y los lenguajes modernos, incorporando elementos simbólicos propios de la cultura mapuche como una forma de reinterpretar y dar un sentido social a su obra. 
La importancia de revelar su trabajo está centrada en su capacidad de visualizar desde la corriente indigenista temáticas que desbordaban los límites del campo artístico, lo que ha permitido dar nuevas interpretaciones a las necesidades sociales, culturales, políticas y económicas de ese momento del pueblo indígena mapuche.

Recibido: 12 de febrero de 2020; ACEPTAdo: 15 de septiembre de 2020 


\section{REFERENCIAS BIBLIOGRÁFICAS}

Artistas Visuales Chilenos (2019). Alberto Valenzuela Llanos [Internet]. Museo Nacional de Bellas Artes [cited 2019 Sep 15]. Available from https://www.artistasvisualeschilenos. $\mathrm{cl} / 658 / \mathrm{w} 3$-article-40032.html.

Artistas Visuales Chilenos (2019). Juan Francisco González [Internet]. Museo Nacional de Bellas Artes [cited 2019 Sep 20]. Available from https://www.artistasvisualeschilenos.cl/658/ w3-article-78055.html.

Artistas Visuales Chilenos (2019). Pedro Reszka Moreau [Internet]. Museo Nacional de Bellas Artes [cited 2019 Sep 12]. Available from https://www.artistasvisualeschilenos.cl/658/ w3-article-39905.html\#bibliografia.

Bicentenarias mujeres en la memoria y en la historia de Chile (2010). Mujeres de la Araucanía. Celia Leyton [Internet]. Available from http://www.bicentenarias.cl/ms_celia_leyton.htm.

Chacana, S. (2012). «Diferenciadores de la textualidad y etnoestética femenina contenida en la colección de trariwe del Museo Regional de la Araucanía». Fondo de Investigación Patrimonial DIBAM.

Chinuailaf, G. (2015). «Habitar el mundo, el ejercicio del reconocimiento», en Diálogos. Arte contemporáneo y su reconocimiento intercultural. Santiago de Chile (Pontificia Universidad Católica de Chile): Centro Interdisciplinario de Estudios Interculturales Indígenas.

Cortés, N. (1953). «Mujeres que hacen noticias», en El Diario Austral. (17 marzo 1953).

De Augusta, F.F.J. (2017). Diccionario Mapudungún-Español. Español-Mapudungún (M. Rojas, ed.). Santiago, Chile: Centro de Investigaciones Barros Arana, Ediciones UC Temuco.

El Diario Austral (1950a). “También los indios son chilenos”, en Reigolil encontró Celia Leyton los más soberbios tipos Mapuches; no la dejaron pintar, pero vió un "Machitún”». El Diario Austral (5 febrero 1950).

El Diario Austral (1950b.) «"Tramites aduaneros argentinos, me impidieron 'ventear' a mis mapuches en Buenos Aires”; Celia Leyton V. sólo pudo exhibir 6 telas: desarrolló gran "labor cultural"». El Diario Austral (21 junio 1950).

El Diario Austral (1950). «A mediados de la semana venidera la pintora temuquense Celia Leyton exhibirá 22 cuadros en Concepción». El Diario Austral (5 diciembre 1950).

El Diario Austral (1952). «Cooperación de las Municipalidades de Cautín y Malleco ha solicitado el comité nacional monumento a Araucanía». El Diario Austral (6 enero 1952).

El Diario Austral (1962). «Concepción del correo indígena en el segundo mural de Celia Leyton. Será inaugurado junto con edificio de correos». El Diario Austral (7 enero 1962).

Ferrando, R. (2012). Y asi nació la La Frontera... Conquista, guerra, ocupación, pacificación. 15501900 (segunda ed.). Temuco: Ediciones Universidad Católica de Temuco.

Foerster, R. y Montecino, S. (1988). Organizaciones, lideres y contiendas mapuches (1900-1970). Temuco: CEM.

Hernández, A., Ramos, N., y Cárcamo, C. (2002). Mapuche Lengua y Cultura. Mapudungun Español Inglés. Santiago: Pehuén.

Huelen (1956). «Celia Leyton», en Diario Austral. (25 de marzo).

Leyton, C. (1968). Rupandungu (vol. 1). Santiago, Chile: Editorial Universitaria. 
Memoria Chilena (2020). Alonso de Ercilla y Zuñiga [internet]. Available from http://www.memoriachilena.gob.cl/602/w3-article-561.html.

Montecinos, S. (1995). Sol viejo, Sol vieja. Lo femenino en las representaciones mapuche. Santiago: Colección mujeres en la cultura chilena. Serman.

Painecura, J. (2011). Charu. Sociedad y cosmovisión en la Platería Mapuche (vol. 1). Temuco: Ediciones UC Temuco.

VARgas, C. (2019). Los aportes de Claude Joseph sobre el mundo mapuche: cultura material y fotografía del Museo Histórico Nacional. Bajo la Lupa. Subdirección de Investigación, Servicio Nacional del Patrimonio Cultural.

Zamorano, P. y Cortés, C. (2007). «Muralismo en Chile: Texto y contexto de su discurso estético». Universum. 22: 254-274. Available from https://dx.doi.org/10.4067/S0718-23762007000200017. 


\section{FIGURAS}

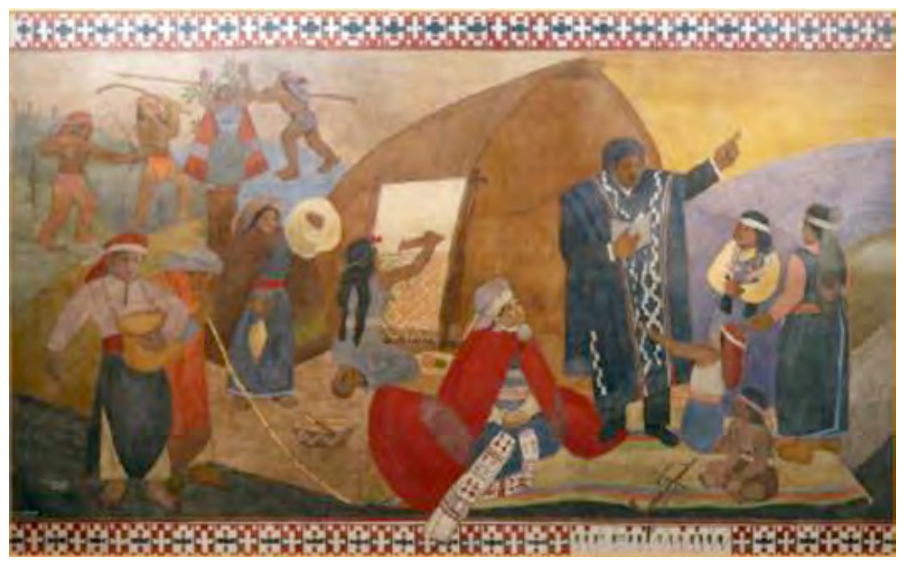

Figura 1. Celia Leyton. Profesor Neculmán. 1956.

Fresco sobre muro de concreto, 5,05 × 3,41 m. Liceo Gabriela Mistral, Temuco.

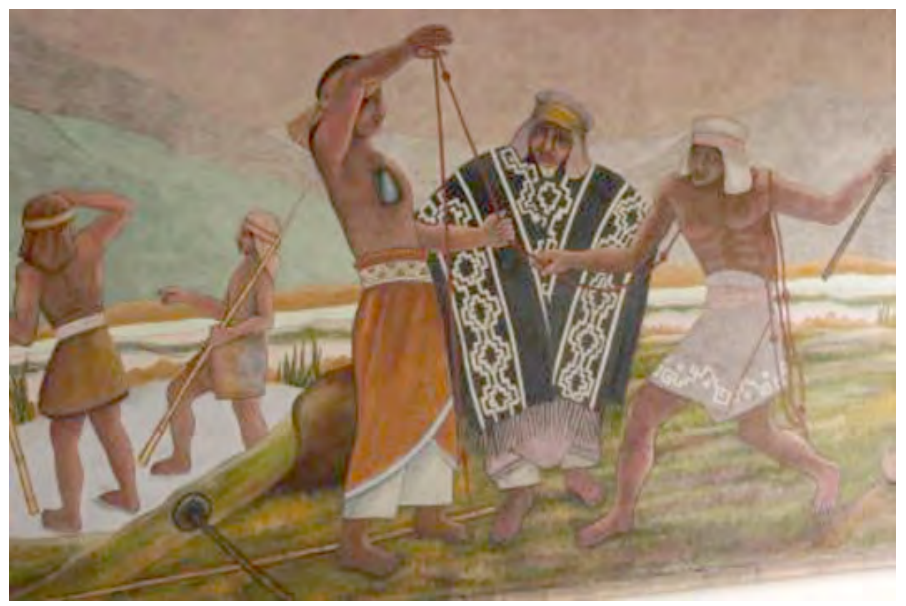

Figura 2. Celia Leyton. Chasqui. 1962.

Fresco sobre muro de concreto, 2,80 × 5,75 m. Correos de Chile en Temuco. 


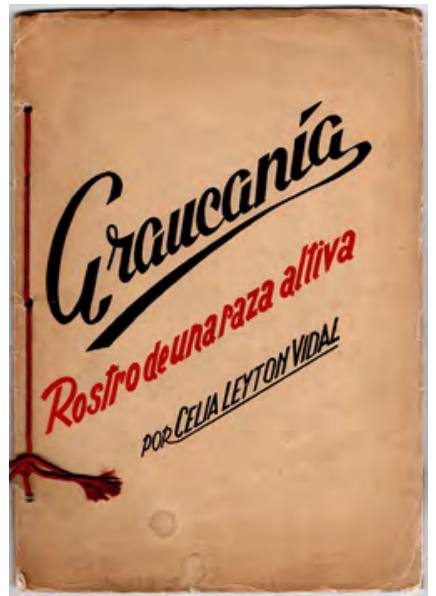

Figura 3. Araucanía, rostro de una raza altiva. Editorial Zig-Zag. 1945.

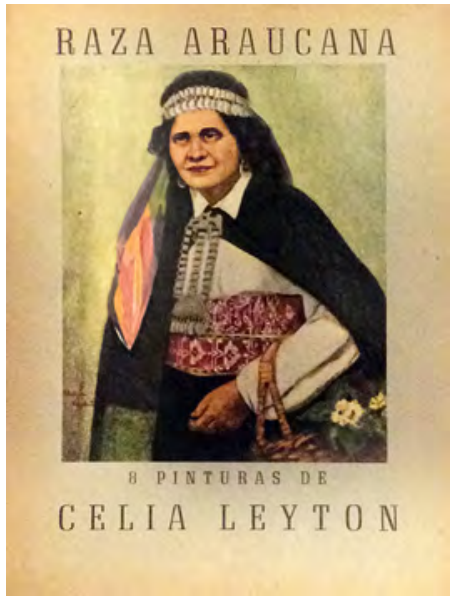

Figura 4. Raza Araucana, 8 pinturas de Celia Leyton. 1950.

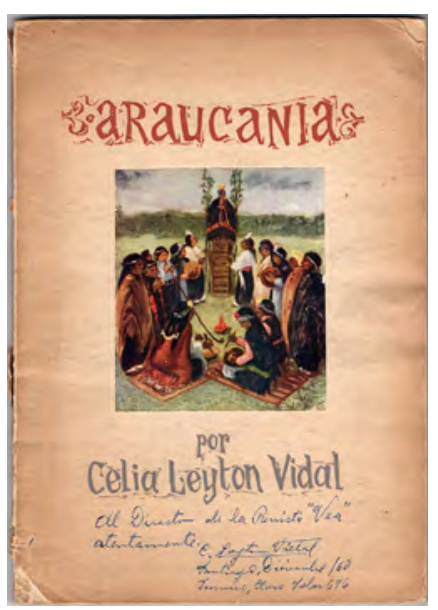

Figura 5. Araucania. 1953.

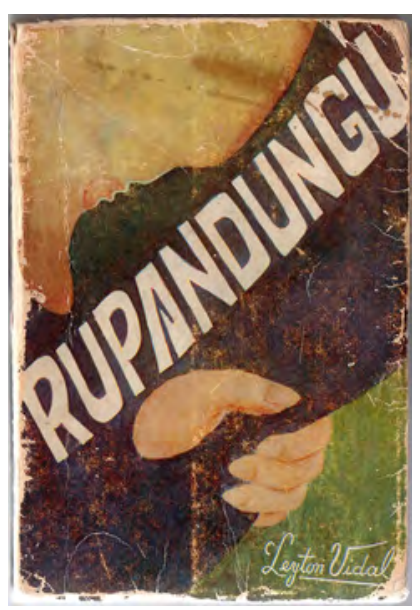

Figura 6. Rupandungú.

Editorial Universitaria. 1968. 


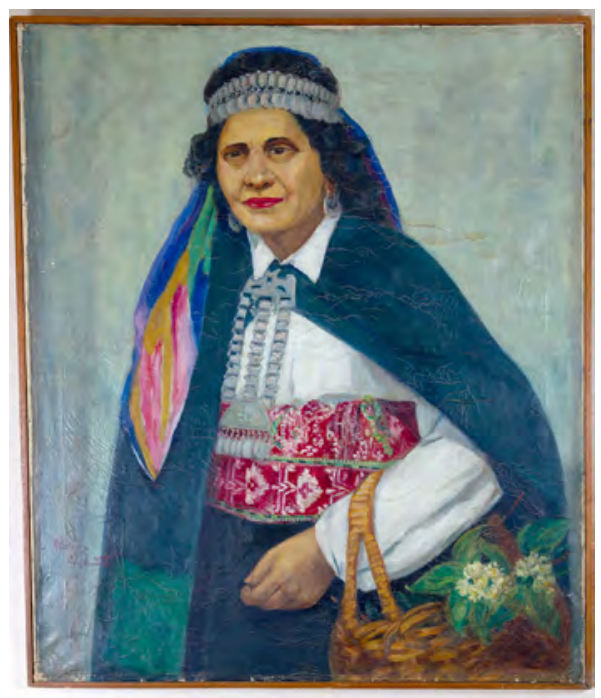

Figura 7. Autorretrato Millakëyen,

Celia Leyton, c. 1950 óleo sobre tela $72 \times 84$.

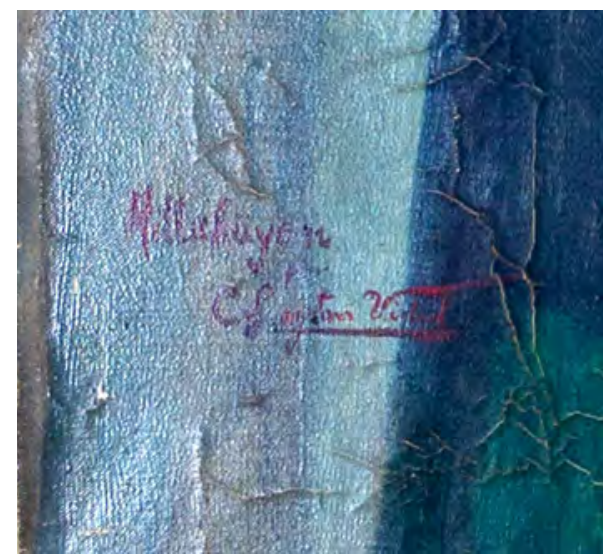

Figura 8. Detalle de firma en pintura donde se puede leer Millaküyén / Celia Leyton.

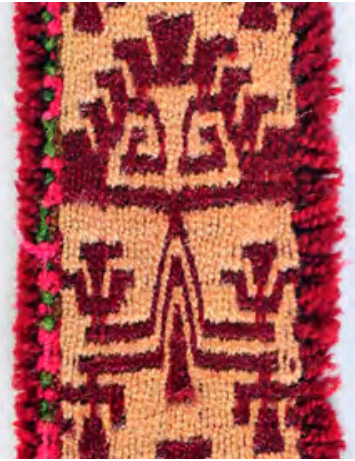

Figura 9. Ícono antropomorfo trariwe.

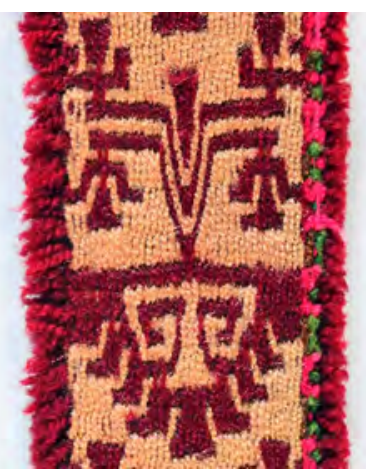

Figura 10. Ícono fitomorfo trariwe. 
